\title{
Recent Progress and Future Innovation of the Japanese Iron and Steel Industry*
}

\section{By Shinroku YAMASHITA**}

\section{Introduction}

The Japanese steel industry has made remarkable growth during the last decade, and many modern steelmaking plants have been built one after another. Steelmaking facilities and operating technology are now at one of the highest levels in the world. Since the oil crisis, however, the increase in the prices of raw materials has been very acute. Furthermore, the regulations for environmental control in Japan have become stricter every year. Thus, the industry is now facing a so-called turning point. Because of this current situation in the industry, I would like to reflect upon the growth achieved thus far and state my personal opinion as to possible action to be taken to cope with this changing situation, placing emphasis on the management of steel plants and the operation of their facilities.

\section{Expansion in the Scale of Steelmaking Plants and Background Information}

The growth of crude steel production in Japan is shown in Fig. 1. As shown in this figure, the construction of many new steel plants began in 1965. All of them were huge steel plants equipped with large blast furnaces having an inner volume of more than $2000 \mathrm{~m}^{3}$ and basic oxygen furnaces with a capacity of larger than $150 \mathrm{t}$. The crude steel production of these plants is shown in the shaded portion (C) of the figure. The figures shown in the portion (B) represent the production of crude steel by the plants where part of the facilities were replaced with new equipment with a larger capacity. From the ratio of production shown in (C) and (B), it is evident that facilities have been modernized extensively, since about 1965.

It is needless to mention that the construction of such huge iron and steel works was motivated by the sudden increase in the demand for steel, but the most significant factor was because construction of large capacity blast furnaces became feasible. Figure 2 shows the trend in the enlargement of blast furnace capacity in Japan. The upper line shows the maxi-

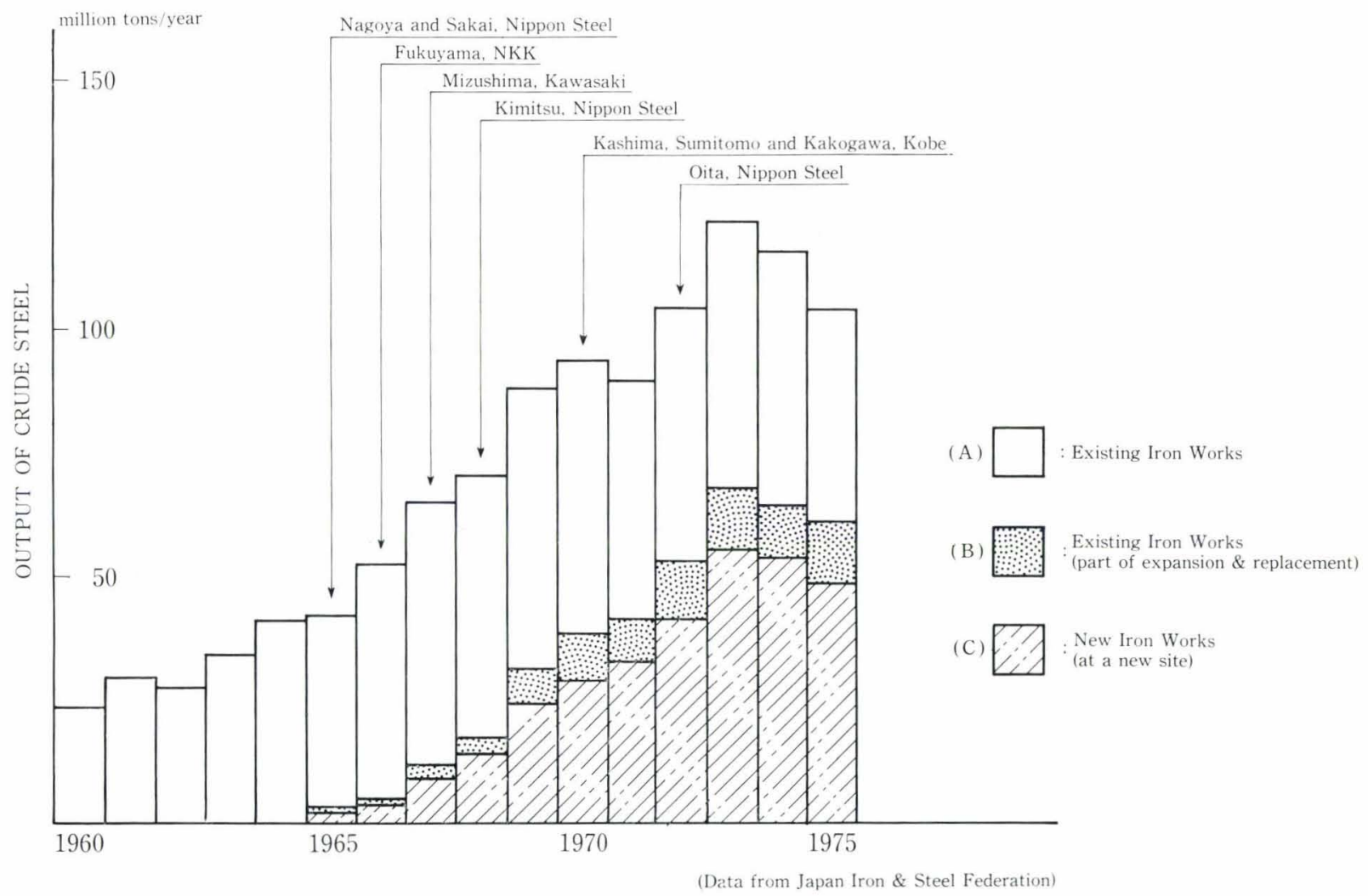

Fig. 1. Modernization of iron and steel works

* Based on the Special Lecture delivered by Mr. S. Yamashita in commemoration of his winning Watanabe Gisuke Prize at the 91 st ISIJ Meeting, April, 1976, at the University of Tokyo, Hongo, Bunkyo-ku, Tokyo 113.

** Azuma Steel Co., Ltd., Nihonbashi, Chūo-ku, Tokyo 103. 


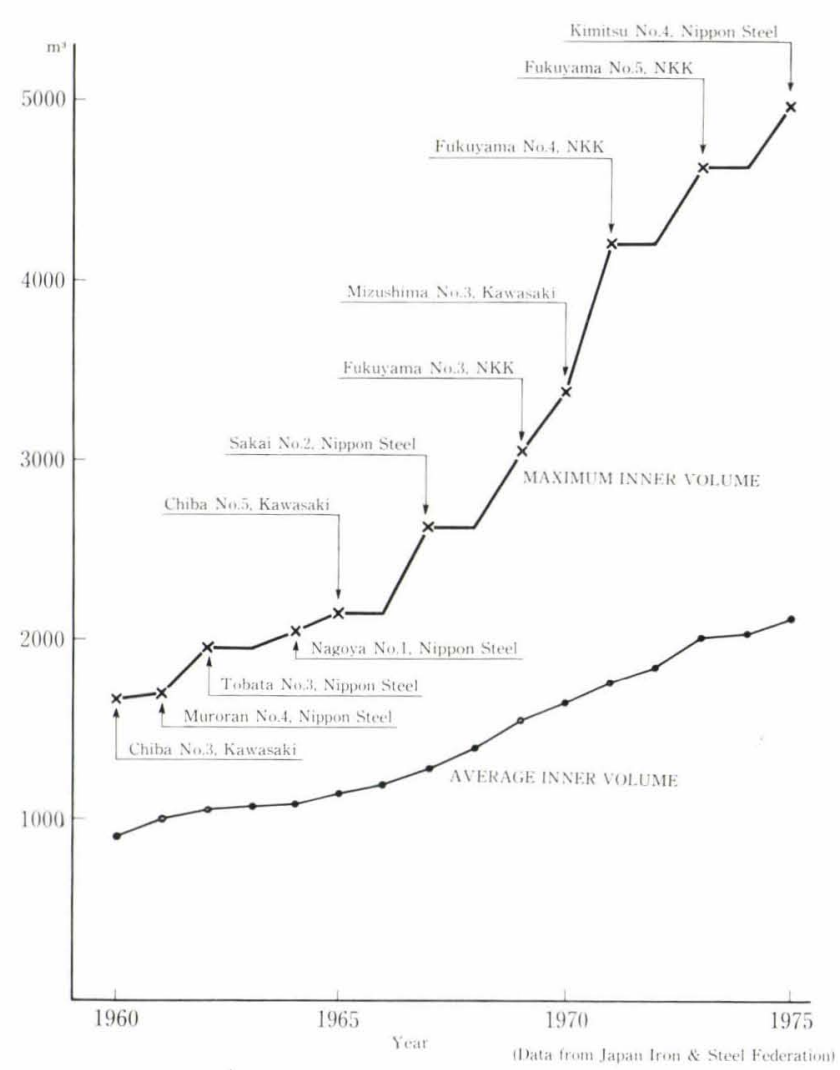

Fig. 2. Progress of blast furnace enlargement

mum inner volume of the blast furnace for each year and the lower line, the mean inner volume of the blast furnaces installed throughout Japan. As is clear from this figure, the enlargement of the blast furnace capacity has occurred quite rapidly, and at present, blast furnaces having an inner volume of more than $5000 \mathrm{~m}^{3}$ and capable of producing hot metal in excess of $10000 \mathrm{t} /$ day have appeared.

A typical production process at a so-called 10 million t steelmaking complex usually consists of steelmaking with large basic oxygen furnaces having capacities ranging from 250 to $350 \mathrm{t}$ supplied by a large quantity of hot metal from huge blast furnaces. This allows production of coils with a huge hot strip mill having an annual capacity of as much as 4 million $t$.

When considering the selection of a site for such a huge steelmaking complex, port facilities for large carrier ships and supply of water should be the priority items.

Since the Japanese steel industry depends upon imports for almost all of its raw material requirements, endeavors have been directed toward the reduction of freight by utilizing large ore and bulk carriers and the size of such carriers has been enlarged each year. Should a large quantity of raw materials be delivered to a works of conventional size by such a large carrier, there would be tremendous fluctuations in the stock level of raw material and the stabilized blending of raw materials would then become difficult. Consequently, the reduction of the cost of raw materials through the use of large carriers has resulted necessarily in the expansion of the scale of the plant.
It is no exaggeration to say that a large scale steelmaking complex must be equipped with a raw material unloading berth having a sufficient depth in order to accomodate large raw material carriers and with a shipment berth having a sufficient length so as to handle a large quantity of finished products, and that these will decide the size of an iron and steel works.

Because a large scale steelmaking complex requires an enormous volume of water, securing of water is a vital question. Figure 3 shows the volume of industrial water consumed by the Japanese steel industry and the rate of its recirculation. At the newly built steel plants, the said rate has been raised to an extremely high level and it is now the common practice at modern steel plants to raise it as high as 95 to $96 \%$. With the recent increase in water charges and as a result of strict regulations for the quality of effluent, this rate tends to rise higher every year.

Many new systems have also been adopted in running large scale steel plants. Particularly notable among these is the utilization of computers. With the conventional method, production planning and scheduling control, for instance, would be confused by handling large amounts of materials and also involve a great deal of employee time. All the processes such as the scheduling of steelmaking, ingotslab application system, instruction of production, control of material and product storage yards, shipment of finished products, etc., are presently being controlled by computers, and a total computer system linking many process computers installed at various locations of production has been developed. The development of computer technology is one of the factors that have enabled the enlargement of steel plants.

As mentioned above, with the intensive use of large scale facilities, continuous, automated or high speed methods have been introduced for manufacturing of steel products. Also, the intrawork transport distance was reduced by rationalizing the layout and application of computer systems. Thus, it has become possible for new steel plants to reduce their labor costs drastically. This has resulted in marked improvement in the productivity of the Japanese steel industry, which has been the key factor for their successful international competition.

\section{Modernization of Steelmaking Facilities at NKK and Its Effect}

The effect of the modernization of steelmaking facilities will be discussed by citing the case of Nippon Kokan K. K. (NKK), as an example.

NKK started the modernization of its steelmaking facilities in about 1955. The Mizue Works was built over the three years from 1959 to 1962 . This works is now an integrated steel plant specializing in the production of sheet and strip products having an annual crude steel capacity of 2 million $t$. In addition, in order to meet the increased demand for steel, plans were initiated in 1965 for the construction of a new steel works in Fukuyama city, Hiroshima Prefecture. Thus began the construction of the world's largest 
iron works capable of producing 16 million $\mathrm{t}$ of crude steel annually. The construction was completed over a period of eight years from 1965 to 1973 .

Because the prevention of pollution has become an important issue in the Keihin district, the replacement of the present iron and steelmaking facilities at the
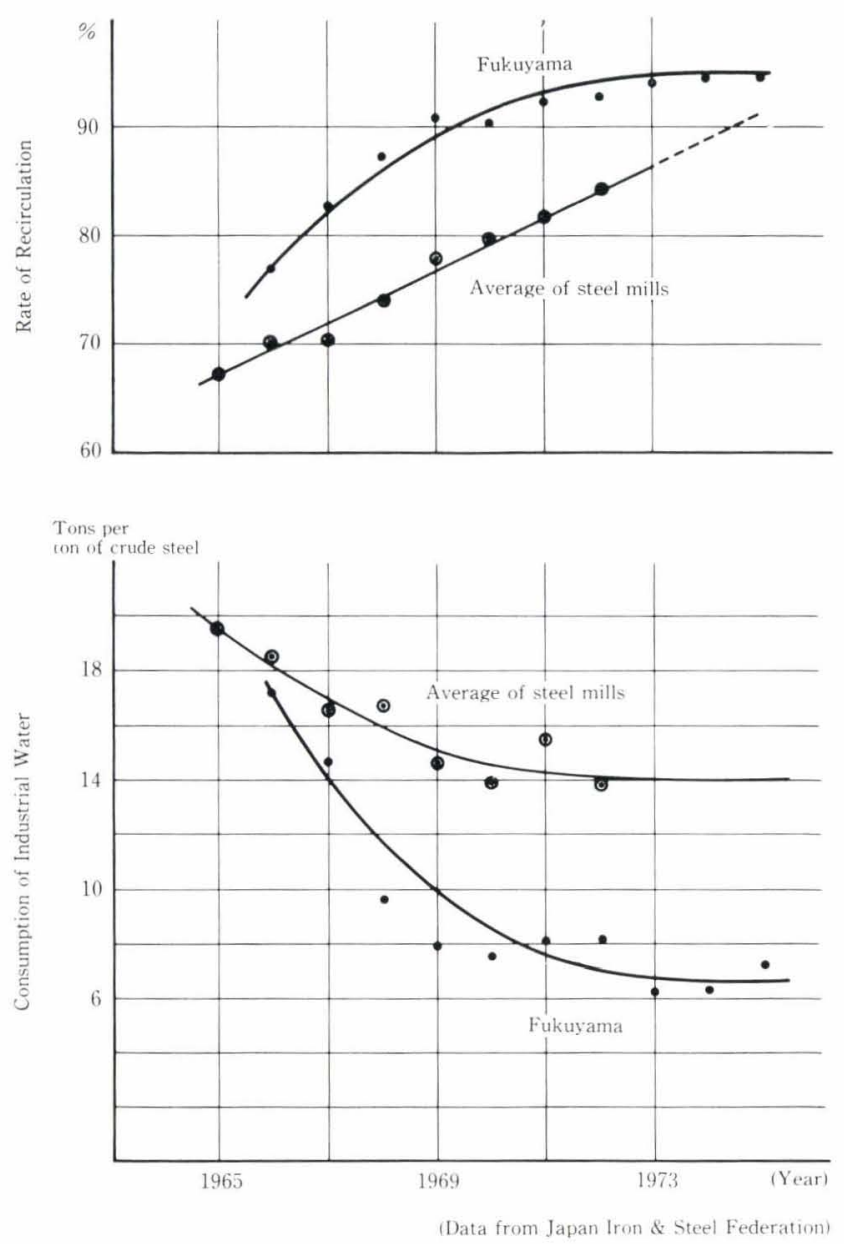

Fig. 3. Use of industry water by Japanese steel industry
Keihin Works with new ones in Ogishima was planned with the intention of the best possible environmental protection and complete renewal of the Keihin Works. Figure 4 shows the Ogishima construction project. In 1968, NKK's three works, Kawasaki, Tsurumi and Mizue, located in the Keihin district were consolidated into one unit under the name of the Keihin Works. In 1971, a reclamation project on Ogishima island, near the Keihin Works, previously used as the raw materials center was begun with the goal of building new iron and steelmaking facilities and rolling mills to replace the older facilities. The island is connected with the existing facilities of the Keihin Works by an undersea tunnel. The old seven blast furnaces at the Keihin Works will be replaced by two large furnaces and the construction of a plant having an annual crude steel capacity of 6 million $t$ is now under way. The final stage of its construction is to be completed in 1978, and the first blast furnace was blown-in in November, 1976.

The total number of employees of the Keihin Works in 1969 when it attained its highest production record of 5.5 million $t$, was 25000 including both direct and contract workers, but plans are underway to reduce this number to 9000 by 1978, the year slated for the completion of Ogishima. Figure 5 illustrates the comparison of labor productivity between Keihin, Fukuyama and Ogishima, which indicates that the productivity of the modern Fukuyama Works is three times that of the Keihin Works. The productivity of Ogishima itself is about two times that of the Fukuyama Works, but overall productivity of the Keihin Works including Ogishima will be about equal to that of the Fukuyama Works because manufacturing facilities of tubular products, which are a low-productivity item, will remain at its existing site.

Energy consumption and inter-plant transportation per ton of crude steel will also be reduced to a level equal to those of the Fukuyama Works after the

Fig. 4. Plan of Ogishima Project

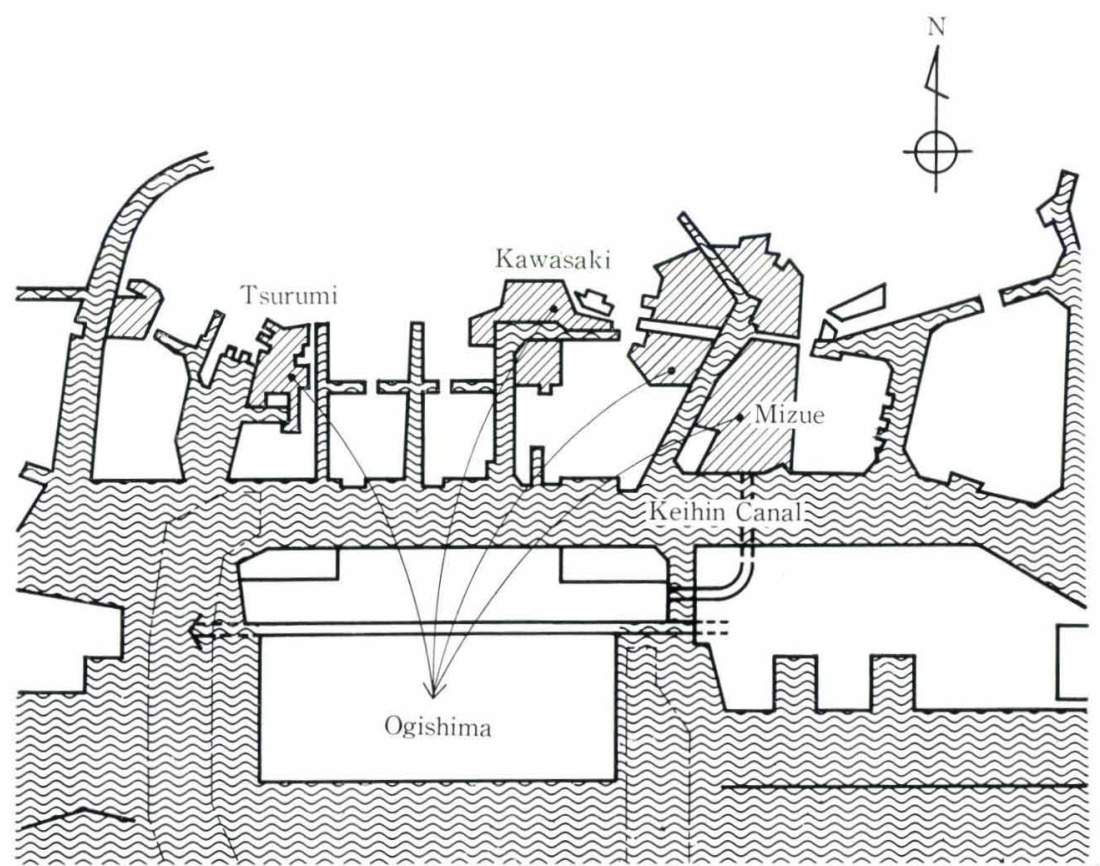




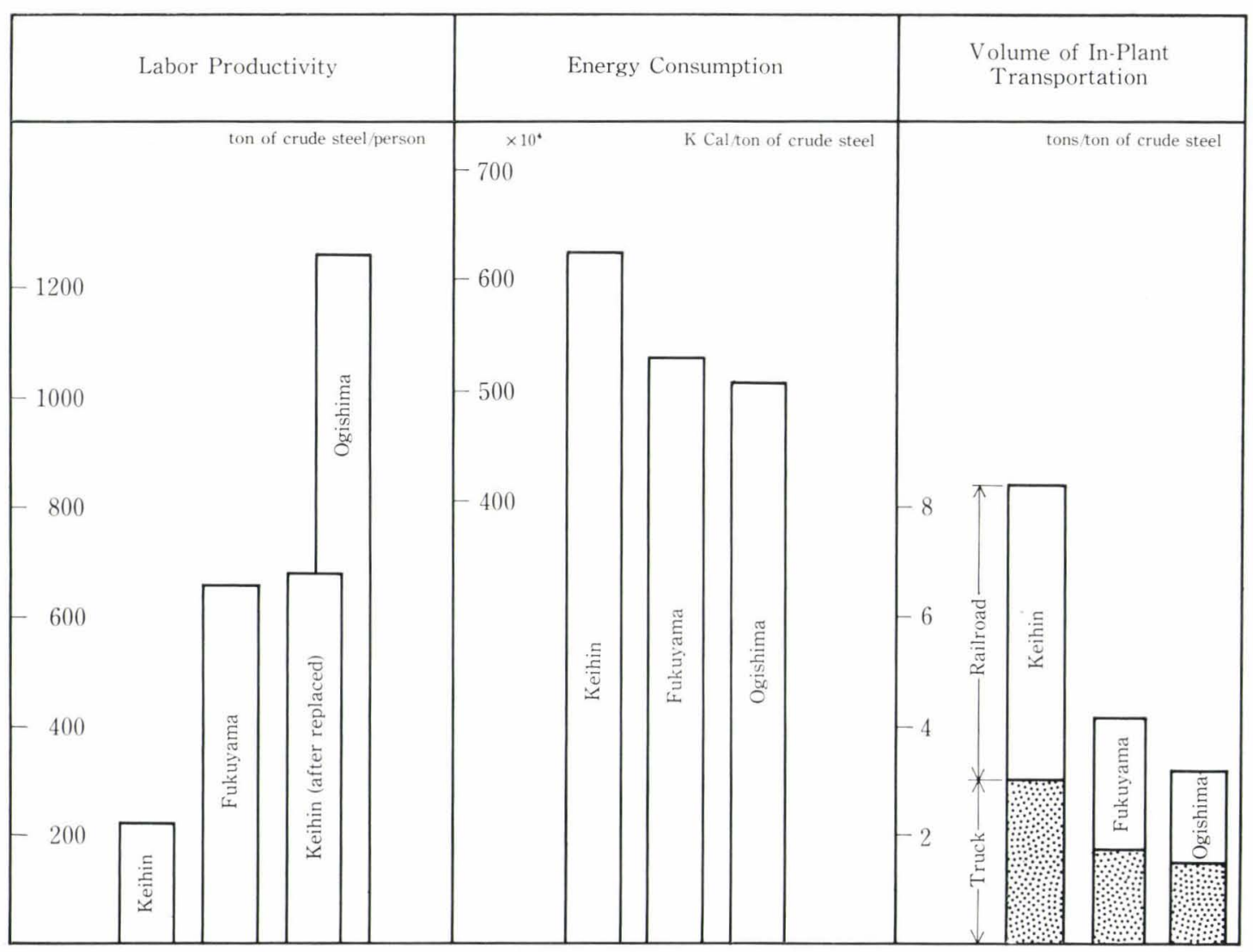

Fig. 5. Comparison between Keihin and Fukuyama performances

replacement.

Figure 6 shows the comparison of the depth of raw material berths and the size of ore carriers at the Keihin and the Fukuyama Works. Because the depth of the present raw material berth at the former is $-10 \mathrm{~m}$ while that of the latter is $-16 \mathrm{~m}$, the average size of vessels being accomodated at the Fukuyama berth is larger by $30 \%$ in freight than that of the vessels coming in the Keihin Works. After the replacement, the depth of the berth at the Ogishima Plant will be $-21 \mathrm{~m}$, and it will be able to accomodate vessels up to 210000 DWT at the maximum, and the freight will be a little cheaper than that of the Fukuyama Works.

Thus, the modernization of steel plants requires massive capital investment, but its effect is enormous on the competitiveness of the products in the international market. Therefore, many steel makers all over the world are exerting their efforts towards the modernization of their facilities.

\section{Future Problems}

As described, the Japanese steel industry has developed steadily but the situation surrounding the industry has changed radically since the oil crisis; that is, the sharp rise in energy costs and the enforcement of stricter regulations for environment. To cope with this situation, a greater effort is being exerted toward the research and development of a means for saving resources and energy as well as towards technology for utilizing industrial waste or preventing pollution. Some of the methods for applying the above research on a commercial scale are as follows.

\section{Formed Coal}

The most serious problem in raw materials is the shortage of coking coal and the resulting rise in its price. Therefore, the emergent problem to be tackled by the industry is how to produce higher quality coke with lower grade coal. As a method for saving on consumption of coking coal, growing attention has been paid to the formed coal process. In this process, part of the coal to be charged into coke ovens (about $30 \%$ ) is formed into briquettes by using a binder. The briquettes thus formed are fed into the coke ovens mixed with the remainder of the coal to improve the strength of coke. By this method, it is possible to substitute part of the coking coal with non-coking coal. This process is also effective in reducing the cost of coal. Non-coking coal may be used for agglomeration in the amount of only several percent. At present, NKK is applying this process for all coal at Keihin and for about one-third of the coal used at Fukuyama.

There is a process known as the "Formed Coke Process" in addition to the formed coal process. Various different types of this process have been studied by many countries. The difference between the formed coal process and the formed coke process is as follows: In the case of the former coke is produced when briquetted coal is fused with the surrounding coal in the carburization stage. In the latter, the formed coal is carburized without changing its shape in special equipment to make it into coke. In the 

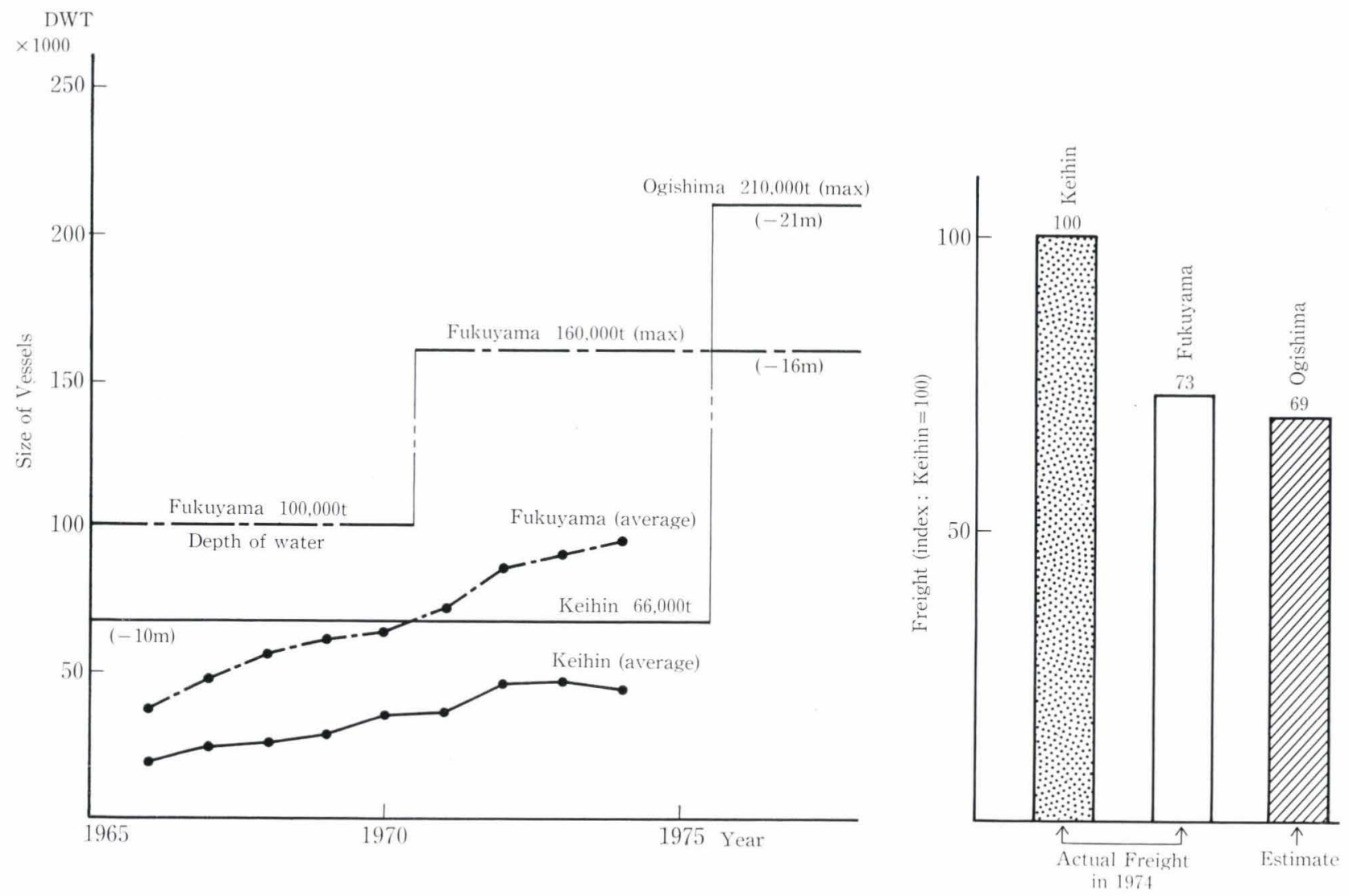

Fig. 6. Size of ore carriers and its relationship with freight

formed coke process, it is possible to blend a large quantity of ordinary fuel coal such as anthracite and non-coking coal, and hence, it has an advantage of being able to select coal freely from wider sources. However, none of the variations of the formed coke process are available on a commercial scale, and therefore, the commercial application of these processes will have to wait until the quality of coke made by these processes in large scale equipment is verified as satisfactory by longterm repeated experimental use in the blast furnace. Furthermore, since these formed coke processes always require the installation of large capacity carbonization equipment instead of a coke oven, it will be considerable time before they are used in commercial application. In the case of the formed coal processes, however, it is possible to use existing coke ovens without any modification and therefore, their use would be effective as a means of coping with the shortage of coking coal.

\section{Coke Dry Quenching}

Since the oil crisis, there has been great concern for the savings of energy, and new equipment and technology has been developed for this purpose. Typical of these is the coke dry quenching (C.D.Q.) process. In C.D.Q., hot coke pushed out from the ovens is quenched with recirculating inert gas instead of water. Figure 7 shows the flow sheet of C.D.Q. Hot red coke is carried to the top of a quenching chamber and dumped into its pre-chamber, therefrom the coke gradually descends to the cooling chamber where inert gas absorbs the heat from the coke for cooling, and then, the coke is discharged from the bottom of the quenching chamber. The gas heated to temperatures of about $800^{\circ} \mathrm{C}$ is led to a waste heat boiler after its dust has been removed to produce the steam for heat recovery. The cooled gas is sent back to the cooling chamber for circulation. NKK is now building five C.D.Q. units, each having a quenching capacity of $70 \mathrm{t} / \mathrm{hr}$ for the coke ovens at Ogishima. The energy recovered from these units would be $3000 \mathrm{kl} /$ month calculated in terms of oil. Because coke produced by C.D.Q. has uniform grain size and no variation in moisture content, it would be a good burden for the blast furnace to achieve its stabilized operation. The conversion of the conventional quenching system to C.D.Q. may be difficult because of the layout of existing coke ovens and the capital expenditure required for conversion, but the C.D.Q. system will be used gradually on newly installed batteries of coke ovens.

\section{Continuous Operation at Various Steps in the Production Process}

In building new steel plants, a great deal of effort has been devoted to achieving continuous operation of the various steps of the production processes in order to save labor. This trend has been further spurred recently to attain savings in energy. A typical example of this is continuous casting. Figure 8 shows the rates of production of slabs or billets via continuous casting in various steel producing nations in the world. Japan is now the highest among those of America and Europe. Japan's rate reached 31\% at the end of 1975 and is expected to increase further thereafter. Both equipment and operating techni- 


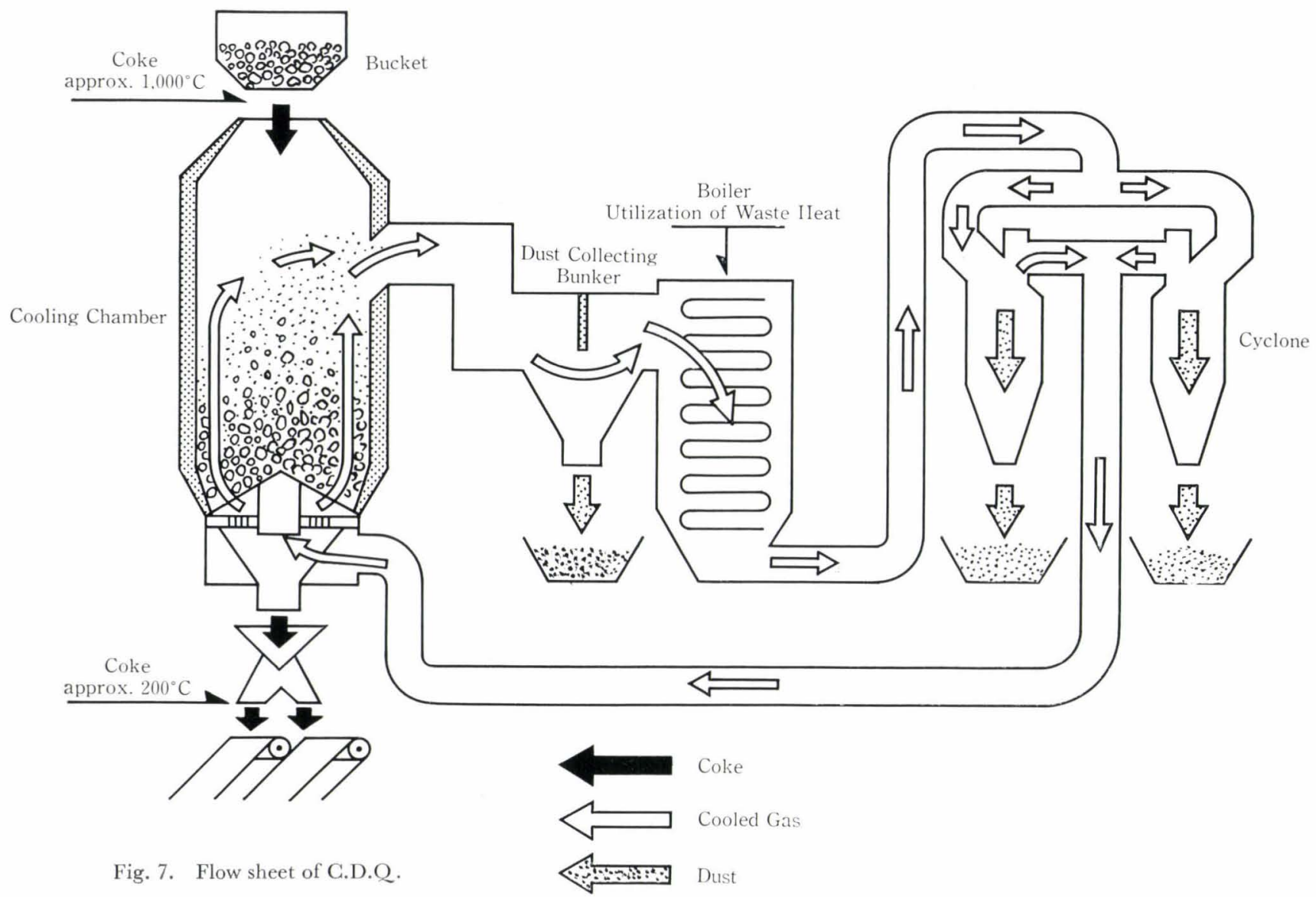

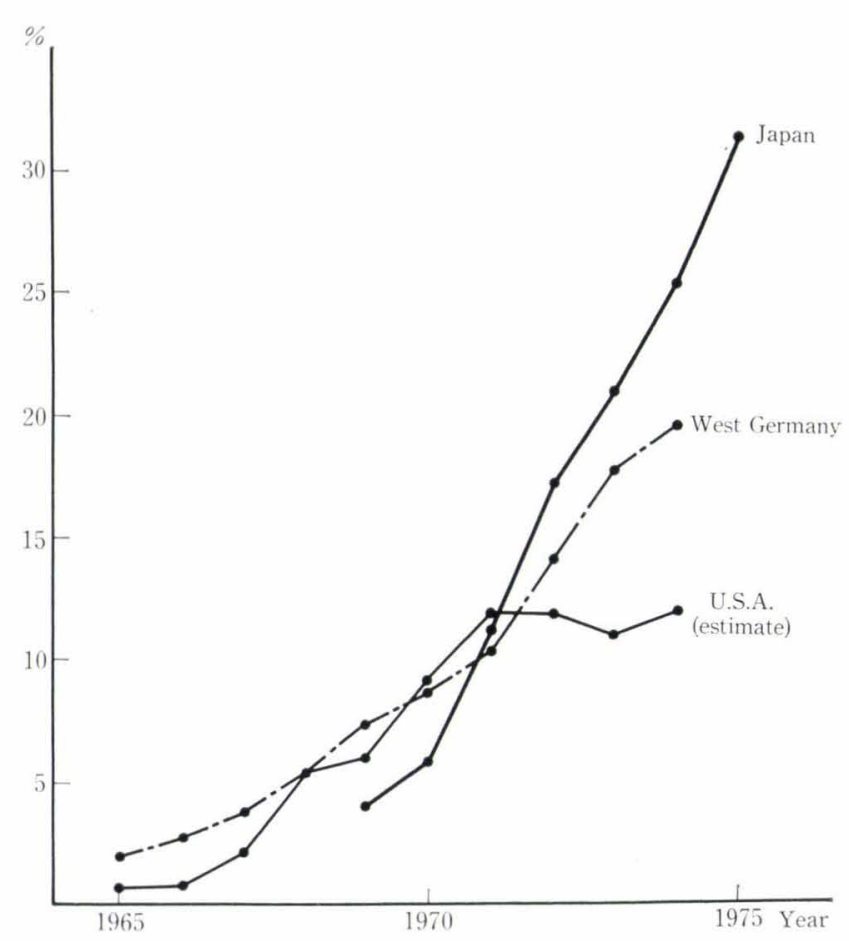

Fig. 8. Ratio of continuously cast steel

ques for continuous casting have been improved greatly in recent years and grades of castable steels have expanded. Thus, the problems involved in producing all semifinished materials via continuous casting would not be the quality of the product but the weight of cast products. Therefore, the problem that remains to be solved would be how to obtain heavier slabs. Another problem connected with continuous casting has been higher construction costs compared to that of the traditional slabbing mill. However, its predominance over slabbing mills has become recently apparent with the rise in fuel costs. In addition to such an economic advantage, it can play a significant role in improving the environment of a teeming operation.

The next step in the continuous operation is the charging of the continuously cast slabs into the subsequent rolling mills without cooling. This has already been performed with some grades of steel. If the surface quality of the continuously cast slabs is improved and surface defects can be removed completely with hot scarfing the rate of this direct charging of hot slabs would be higher. In this respect, it would be also necessary to adjust the operating schedules of the continuous casters and rolling mills, but this would not be a difficult problem to solve.

Other notable continuous processes are the continuous cold rolling and the continuous annealing, which were developed in Japan. No details of these processes will be given here, but the success of the continuous cold rolling process was due to the development of computer technology enabling automatic gage changing during rolling. Thus, this increased the rolling capacity of the mill by $50 \%$ and improved the yield because off-gages could be eliminated almost completely.

Systems for continuous annealing of black plate for use in producing tin plate have been in operation 
for a long time. However, the application of this technology for annealing cold rolled sheet coils for drawing quality was difficult because the annealing time was not long enough to ensure ductility of steel. Recently, however, as a result of the development of annealing technology by a special heat cycle, its use has become possible for the production of cold rolled sheet of deep drawing quality. By using this system, it is possible to anneal the steel in only several minutes compared to the week or so required by the conventional annealing process. It is also possible to process steel continuously, since it combines in one unit such processes as electrolytic cleaning, annealing and temper rolling.

Consequently, it enables considerable reduction in the costs of construction and operation, resulting from considerable savings in the annealing time, manpower and overall annealing shop space, since there is no need to transport and store the products in process within the shop.

With a combination of the continuous cold rolling and the continuous annealing processes, it would be possible to simplify the complicated process of cold reducing including the repetition of uncoiling and recoiling, etc. With these two continuous processing systems, it is expected that a new type of cold reducing mill will be realized. Figure 9 illustrates the comparison between the new continuous system and the conventional system. As is clear from this figure, the new continuous process is able to combine in one unit five separate processes. Of course, there are still many problems to be solved before a fully continuous operation is attained. However, because of the savings in manpower and energy as well as the substantial reduction in construction costs, increased effort will be directed towards the adoption of a fully continuous process.

\section{Disposal of Slag}

Assuming that 100 million $\mathrm{t}$ of steel are to be produced annually by the blast furnace process, a huge amount of slag, in excess of 40 million t, consisting of about 28 million $\mathrm{t}$ of blast furnace slag and approximately 13 million $t$ of basic oxygen furnace slag will be produced in a year. Figure 10 shows the use of blast furnace slag in various steel producing nations. In Japan, about $70 \%$ of the slag produced in 1974 was used as road ballast, concrete aggregate, granulated slag cement, etc. Some of the remaining $30 \%$ was used by steel companies for their own construction and land reclamation, but a considerable amount was wasted. Because the regulations for land reclamation are becoming stricter recently, large steel plants in Japan are troubled with the difficulty of securing places where they can dump waste slag. In the United States, however, the rate of use of slag is higher than Japan and the percentage of steel companies' own use and waste is only 14\%. In FR. Germany, slag is fully utilized in some applications without waste. With the view of energy saving, slag should be utilized as much as possible. The recent rise in oil prices has resulted in an increase in the calcining cost of cement clinker and blast furnace slag cement has been evaluated again and its use will be increased to a level prevailing in USA and Europe. On the other hand, basic oxygen furnace slag has a more limited field of application than blast furnace slag and is being wasted more than the latter. Also in view of energy saving, it is desirable to use it as blast furnace burdens but only a small amount is being returned to blast furnaces at present, because only a limited amount can be used for its stable operation. Thus the effective use of basic oxygen furnace slag is one of the most important problems encountered.

Furthermore, in order to raise the rate of utilization of slag, a committee to explore utilization of slag as a resource has been formed in the Japan Iron and Steel Federation. An all out effort is being made by the total industry for utilization and the result of their effort is eagerly anticipated.

\section{Prereduced Pellet Manufacturing}

In respect to the utilization of waste materials, there is also the problem of dust coming off from blast furnaces and BOF's. Since the dust from these facilities contains higher iron, part of it is being used as the raw material in the manufacture of sintered
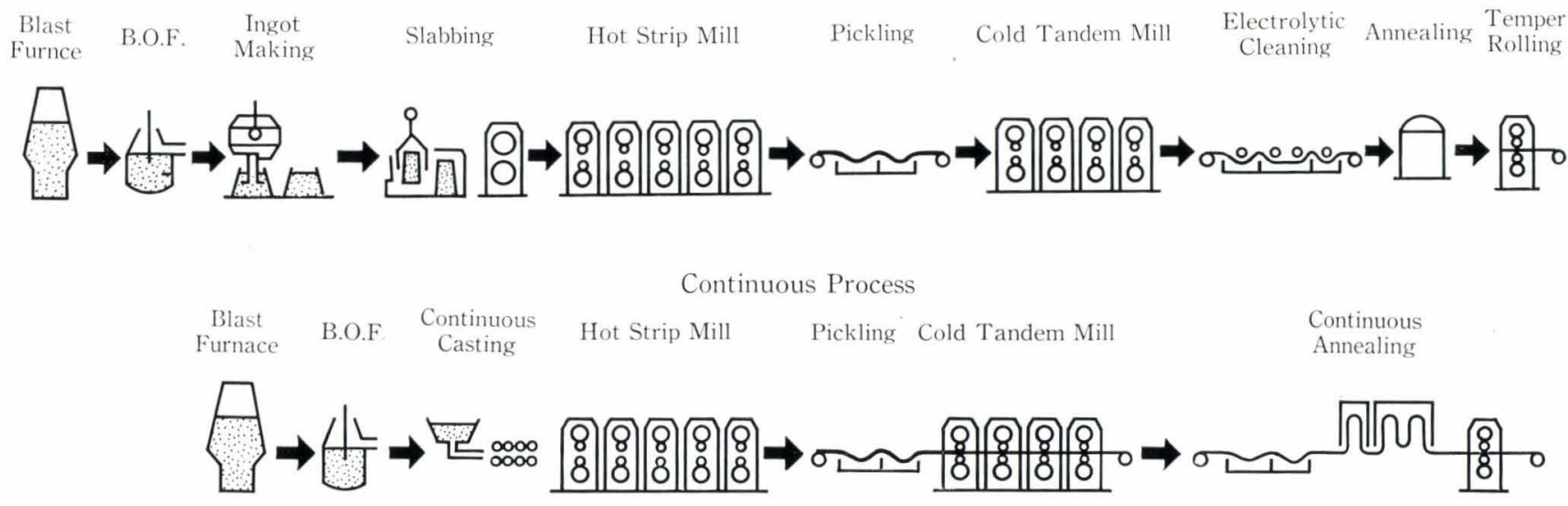

Fig. 9. Example of continuous process 


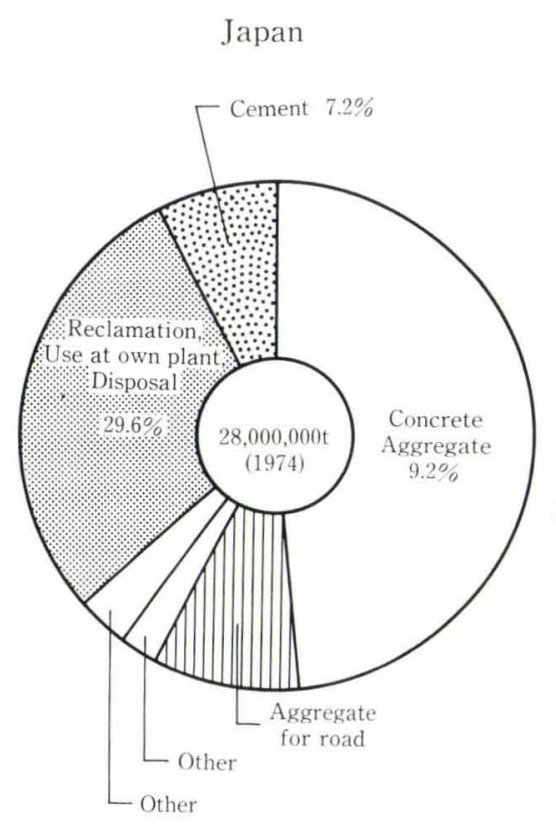

U.S.A.

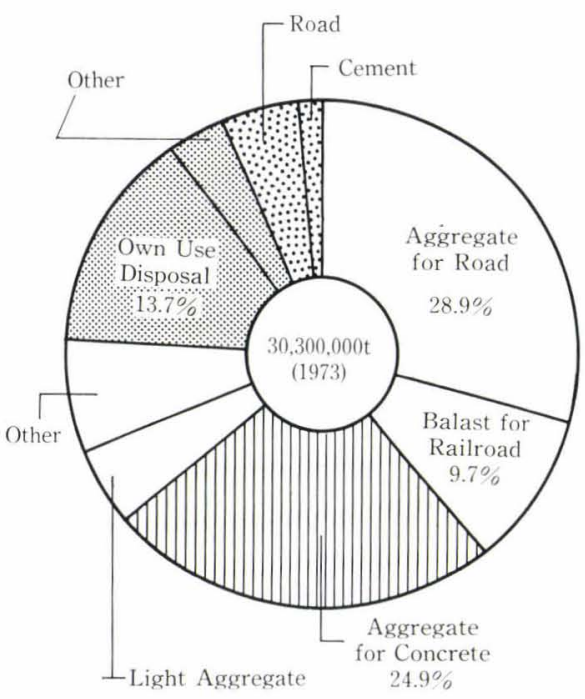
\begin{tabular}{ll}
\hline & Water Granulated \\
Slag
\end{tabular}
West Germany

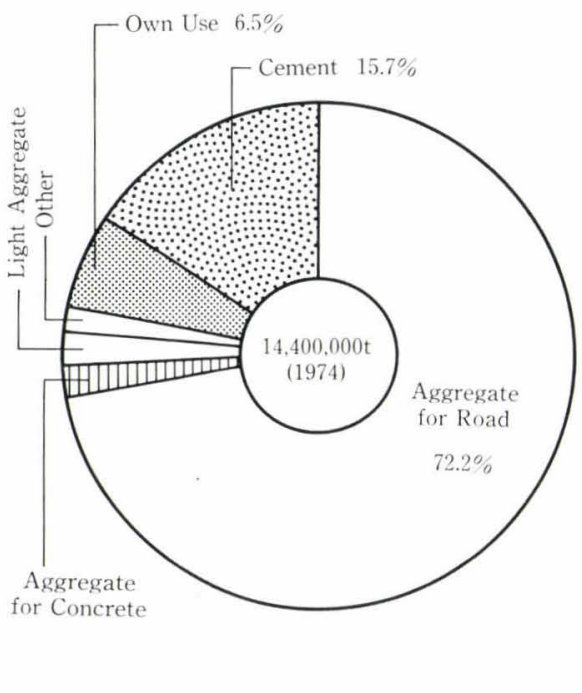

\% ; Unprocessed

Fig. 10. Utilization of blast furnace slag

Raw Material Hopper
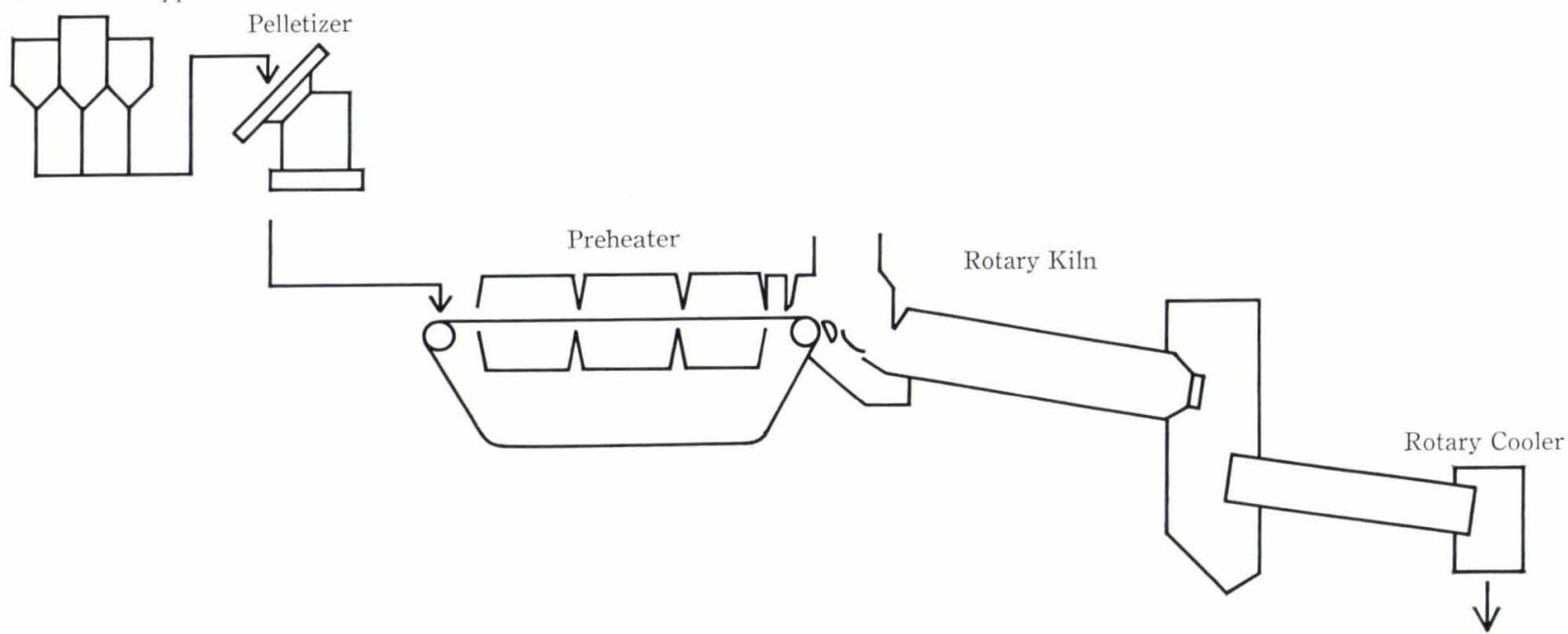

Fig. 11. Flow sheet of SL/RN process

Reduced Pellet

ore. However, since zinc in the dust cannot be removed during sintering, the use of dust containing higher zinc results in sintered ores having a higher zinc content. As a consequence, if the blast furnace is fed with sintered ore mixed with a higher rate of the dust repeatedly, the zinc content in the hot metal is enriched resulting in trouble in the operation of the blast furnace. For this reason, reduced pellet manufacturing using the dust decreased and without zinc have attracted much attention as a means for both utilization of resources and disposal of waste materials. For the purpose of disposal and utilization of the dust generating from the blast furnace and BOF, NKK has installed a plant to manufacture reduced pellets (SL/RN Process) at the Fukuyama Works, and shown in Fig. 11 is the flow diagram of its principal process steps. This process uses a mixture consisting of about
$70 \% \mathrm{BF}$ and BOF dust and 30\% fine ore, which, after pelletized, passes through the preheating zone and is made into a reduced pellet in a rotary kiln using coal as a reductant. The reduced pellets so produced are fed into the blast furnaces or BOF depending upon the degree of reduction. The plant has a capacity of $350000 \mathrm{t} / \mathrm{yr}$. Such a reduced pellet plant is an indispensable means for a large steel plant for full utilization of the resources and disposal of the waste material.

\section{Environmental Control}

Efforts have been increased by the Japanese steel industry to meet the strict regulations for environmental protection and the capital expenditures for pollution control throughout the industry generally go on increasing. This trend is shown in Fig. 12, 


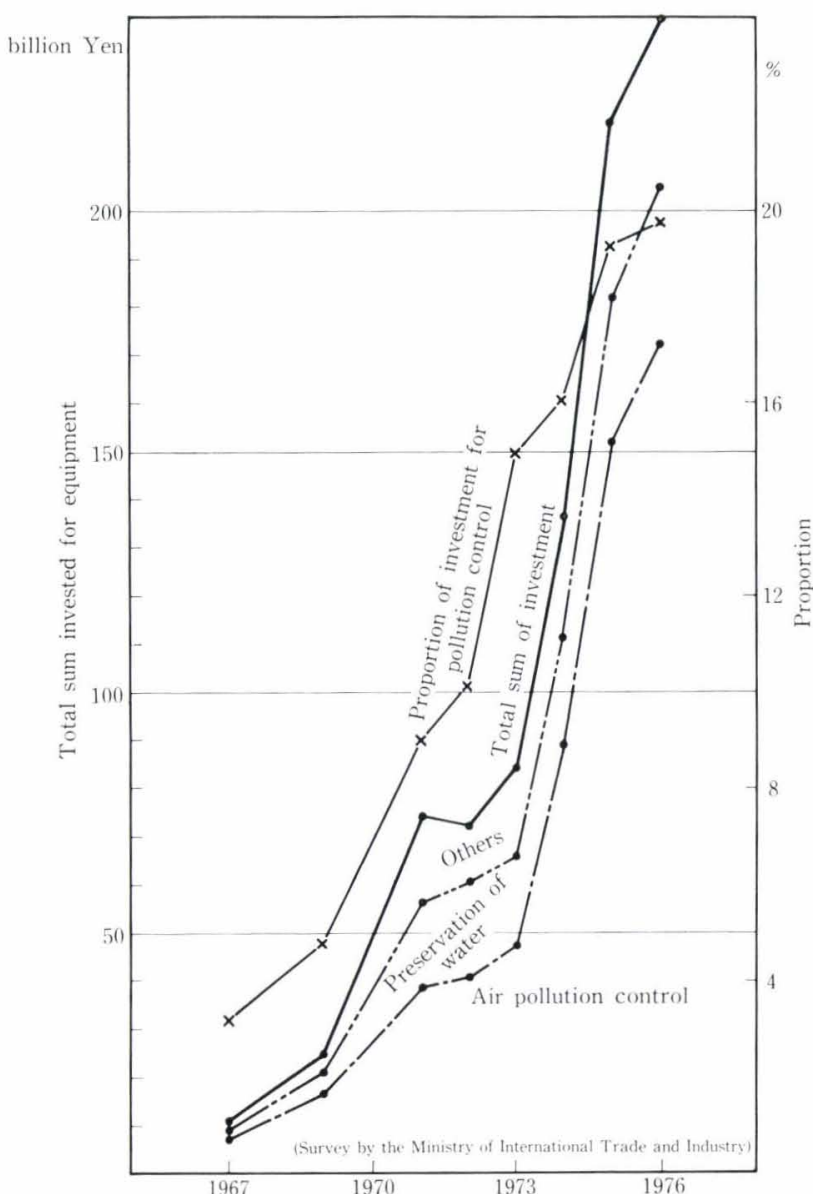

Fig. 12. Investment by Japan's steel industry for pollution control equipment

from which it is noted that the total expenditure for pollution control, during the fiscal year of 1975 , reached 210 billion yen, which was nearly $20 \%$ of the total capital investment made by the industry during the year. The energy required to operate pollution control facilities has also increased gradually and as in the case of NKK, electric power consumed for pollution control came to about $25 \%$ of the total power consumed for the operation of its entire plant. As the result of these efforts, factory surroundings have been improved greatly, but the pollution control expenditures have become a major factor for pushing up production costs of steel.

The most important issue at present is the control of nitrogen oxides $\left(\mathrm{NO}_{\mathrm{X}}\right)$, for which the Japanese Government has established the strictest regulations in the world. Unfortunately, however, the technology for controlling $\mathrm{NO}_{\mathrm{X}}$ emission is still in the de- velopmental stage and the regulations proceed the tempo of technological development. The steel industry is making every effort to combat this problem by appropriating a special fund for development and also organizing a research association in the Japan Iron and Steel Federation. The fund provides the related industries and universities with the necessary capital required for research work while at the same time the association is conducting a study on the removal of $\mathrm{NO}_{\mathrm{x}}$ of exhaust gases from sintering plants jointly with nine steel manufacturers in Japan. Since the exhaust gas from the sintering oven contains quite a bit of dust compared to other types of sintering equipment, it is said that removal of $\mathrm{NO}_{\mathrm{X}}$ is more difficult, but they are now exerting efforts vigorously to overcome this difficulty.

\section{Conclusion}

The Japanese iron and steel industry now possesses a much higher proportion of modern facilities than those of Europe and U.S.A., as a result of an early start in modernization programs after the war. This is the decisive factor that has enabled the Japanese steel industry to maintain its supremacy in international competition. However, selection of sites for new steel plants has become more difficult because of the strict regulations for environmental preservation, and as a consequence, the industry's approach to future capital spending should be directed towards the improvement of the environment through the replacement of older facilities and increases in productivity. The steel industries in other nations are in a similar situation and they are exerting efforts to modernize their facilities, and hence, the difference in productivity between Japanese and foreign steel industries will decrease gradually. The Japanese steel industry depends upon the supply from overseas of raw materials and energy and is at a handicap with higher interest rates and pollution control expenditures. Whether or not the Japanese steel industry can overcome these difficulties and maintain its competitive position in the world market depends solely on the development and advancement of its technology.

It would be difficult for the Japanese steel industry to continue the rapid growth it has attained in the past, but I firmly believe that it will continue to grow steadily, supported by excellent steelmaking technology and new, modern facilities. 